\title{
Induced systemic resistance to Meloidogyne spp by $\beta$,amino butyric acid in tomato
}

\author{
Shamaael S. Mutar, Farkad A. Fattah \\ Department of Plant Protection, College of Agriculture, University of Baghdad, Baghdad, Iraq; \\ *Corresponding Author: farkad.fatah@gmail.com
}

Received 17 September 2013; revised 16 October 2013; accepted 27 October 2013

Copyright (c) 2013 Shamaael S. Mutar, Farkad A. Fattah. This is an open access article distributed under the Creative Commons Attribution License, which permits unrestricted use, distribution, and reproduction in any medium, provided the original work is properly cited.

\begin{abstract}
$\beta$,amino butyric acid (BABA) induced resistance against Meloigogyne spp in tomato. Significantly $(p=0.05)$ less, 41.11 second stage juveniles (J2) enter the roots of treated than, 116.66 $\mathrm{J} 2$ in untreated control plants. Root fresh and dry weight ( $R f w, R d w)$ were 2.87 and $0.12 \mathrm{~g}$ in treated compared with 4.78 and $0.30 \mathrm{~g}$ in nematode infected control plants respectively, $30 \mathrm{~d}$ after nematode inoculation. Sfw and Sdw were 8.62 and $0.60 \mathrm{~g}$ compared with 3.94 and $0.22 \mathrm{~g}$ in control plants. Foliage spray at 40 and $20 \mathrm{mM}$ of BABA was more effective than 10 and $5 \mathrm{mM}$ treatments. The former two concentrations recorded the lowest, average gall index, $2.11 \mathrm{com}$ pared with $3.33,4.11$, and 5 for the latter two concentrations and nematode infected control respectively. Results also indicated that treatments with BABA prior to nematode inoculation were superior in inducing resistance to Meloidogyne spp over treatment at the time or after nematode inoculation.
\end{abstract}

Keywords: Induced Resistance; $\beta$,Amino Butyric Acid; Meloigogyne spp; Tomato

\section{INTRODUCTION}

Tomato, Solanum lycopersicum L., formerly known as Lycopersicon esculentum Mill., is the second most important vegetable crop after potato with annual world production of about 152.9 million ton in 2009 [1]. Annual tomato production in Iraq was estimated at 830.000 tons in 2008 [2]. Tomato plants are subjected to infection by many important plant pathogens including the root knot nematodes, Meloidogyne spp which are considered as the most important nematode species worldwide and in Iraq. Many effective control measures were used to manage these pathogens such as soil solarization chemical and biological control. Induced systemic resistance to plant pathogen provides an ideal control measures against plant pathogens [3]. Chemical, physical and biological inducers to control the root knot nematodes were used [4]. In recent years, various chemical, physical and biological agents were used to induce resistance to many plant pathogens. $\beta-1,3$ amino butyric acid (BABA), Benzol [1-3] thaiadiazole-7-carbothionic acid S-methyl ester and salicylic acid are among the most widely studied chemical inducers [5-7]. These chemicals activate resistance against different plant pathogens like fungi, bacteria, viruses and nematodes [8]. BABA was reported to induce resistance against members of solanacea, cucurbitacea, legumenacea, cruciferea, and rosacea [9]. Jakob et al. [10], reported that BABA induced resistance to different plant pathogens such as fungi, bacteria, viruses, and plant parasitic nematodes. Only few studies on induced resistance by BABA against plant nematodes are reported. BABA was reported to reduce damage due to root knot nematode on tomato [11] and M. javanica and Rotylenchulus reniformis on pineapple [12] and induce resistance against $M$. javanica in cucumber [4].

This study was undertaken to assess the ability of $\beta$, aminobutyric acid to induce acquired systemic resistance against the root knot nematodes, Meloidogyne spp in tomato plants.

\section{MATERIALS AND METHODS}

Experiments were performed in a greenhouse (27 \pm 5 C) and tomato, Solanum lycopersicum L. cv. "Supper Regina” highly susceptible to Meloidogyne spp was used. Plants were grown and maintained in $1 \mathrm{~kg}$ plastic pots throughout the experiments.

\subsection{Nematode Inoculation}

Soil from cucumber grown plastic house heavily in- 
fested with Meloidogyne spp (predominantly M.javanica) were collected and stored at $4 \mathrm{C}$ in polyethylene pages until use to inoculate tomato seedlings. The nematode infested soil was mixed with peat moss in 1:1 ratio and used as nematode inoculums.

\subsection{Preparation $\beta$,Amino Butyric Acid (BABA)}

Stalk solution of BABA, Mwt = 103 (Sigma Aldrich, St Louis, Missouri, USA) was prepared by dissolving $412 \mathrm{mg}$ in $100 \mathrm{ml}$ of distilled water.

\subsection{Foliage Treatments with $B A B A$}

Four concentrations of BABA, 5, 10, 20, and $40 \mathrm{mM}$ were used as foliage application. The experiment was consisted of 13 treatments (one nematode inoculated control sprayed with distilled water and 12 combination of the 4 concentrations of BABA 3-d before, during and 7-d after nematode inoculation). Plants were carefully sprayed till complete wetness using $1 \mathrm{~L}$ hand sprayer. Each treatment was replicated 4 times and arranged in randomized complete blocks in the greenhouse. Thirty days after inoculation, plants were assessed for growth and nematode infection.

\subsection{Root Treatments with BABA}

In this experiment, $2 \mathrm{~mL}$ of $1,2.5$ and $5 \mathrm{mM}$ of BABA were used as soil drenching added around the stem of single tomato plants growing in nematode infested soil in $1 \mathrm{~kg}$ plastic pots. Ten treatments (one nematode inoculated control watered with $2 \mathrm{ml}$ of distilled water and 9 combinations of the 3 concentration of BABA applied 3-days before, during and 7-days after nematode inoculation ). Thirty days after inoculation, plants were assessed for growth and nematode infection. Each treatment was replicated 4 times and arranged in a randomized complete block in the greenhouse. Thirty days after inoculation, plants were assessed for growth and nematode infection.

\subsection{Effect of BABA on Meloidogyne spp Rate of Gall Index}

The rate of infestation of the root knot nematodes is determined using a 5 level scales [13]: $1=$ no galls on roots, 2 = galls on $1 \%-25 \%$ of the root, $3=$ galls on $26 \%-50 \%$ of the root, $4=$ galls on $51 \%-75 \%$ of the root, and 5 , galls on $76 \%-100 \%$ of the root.

\subsection{Effect of BABA on Fresh and Dry Weight of Shoot and Root Systems}

Plants were carefully uprooted and roots were washed under tap water to remove adhering soil. To determine shoot and root dry and wet weight, shoots and roots were separately weights and dried at $70 \mathrm{C}$ for $48 \mathrm{~h}$ or until weight fixed.

\subsection{Effect of BABA on Nematode Penetration}

To determine the effect BABA treatments on nematode penetration of tomato roots, roots were stained with acid fuchsine [14], washed with water to remove excess stain and $1 \mathrm{~g}$ of each root was individual examined under a compound microscope to count nematodes inside the roots.

\section{STATISTICAL ANALYSIS}

The data were subjected to analysis of variance and means were separated by the least significant method at ( $p=0.05)$ using SAS, 2004 [15].

\section{RESULTS}

\subsection{Foliage Application}

\subsubsection{Effect of Foliage Treatment of BABA on Meloidogyne spp Rate of Gall Index}

BABA treatment induced resistant to Meloidogyne spp in tomato plants (Table 1). The treatments significantly ( $p=0.05$ ) reduced the rates of gall index of treated plants compared with nematode infected control plants. While $40,20,10$, and $5 \mathrm{nM}$ of BABA treated plants recorded low average gall indices, 2.11, 2.11, 3.33, 4.11 respectively. BABA untreated plants recorded the highest average gall index, 5, 30 days after nematode inoculation. The former two concentrations render tomato plant sig-

Table 1. Effect of spraying BABA on tomato, Solanum lycopersicum L. shoot on rate of root galls index of Meloidogyne spp infected plants 30 days after nematode inoculation.

\begin{tabular}{ccccc}
\hline \multirow{2}{*}{$\begin{array}{c}\text { BABA Conc. } \\
(\mathrm{mM})\end{array}$} & \multicolumn{3}{c}{ Rate of root gall index } & \multirow{2}{*}{ Mean } \\
\cline { 2 - 4 } & 7 days before & During & 3 days after & \\
\hline 40 & 2.33 & 2.33 & 1.66 & 2.11 \\
20 & 2.66 & 2 & 1.66 & 2.11 \\
10 & 4 & 3 & 3 & 3.33 \\
5 & 4 & 4 & 4.33 & 4.11 \\
Control & 5 & 5 & 5 & 5 \\
Mean & 3.60 & 3.26 & 3.13 & \\
\hline
\end{tabular}

$\operatorname{LSD}(P=0.05)=$ Conc. $=0.35^{*}$,Trea. $=0.27^{*}$, Inter $=0.60^{*}$. Each number is a mean of three replicates and two plant each. "Indicate significant deferens. Nematode inoculums (nematode infested soil + peat moss, 1:1) were added when plants were 4 - 5 true leaves. Gall index was according to 1 - 5 level scale: $1=$ no galls on the roots, $2=$ galls on $1 \%-25 \%$ of the root, $3=$ galls on $26 \%-50 \%$ of the root, 4 = galls on $51 \%-75 \%$ of the root, and $5=$ galls on $76 \%-100 \%$ of roots. BABA $=\beta$, amino butyric acid. 
nificantly more resistant to the nematode than the two latter concentrations (Table 1). The 40 and $20 \mathrm{mM}$ scored significantly $(p=0.05)$ the lowest nematode gall index, 1.66, when BABA treatments exceeded nematode inoculation by 3 days compared with other test treatments.

\subsubsection{Effect of BABA on Fresh and Dry Weight of Root Systems}

Results in Table 2 showed that spraying tomato plants with BABA significantly $(p=0.05)$ affected root fresh weight (Rfw) and root dry weight (Rdw) of Meloidogyne spp infected tomato plants. The $40 \mathrm{mM}$ recorded the lowest average root weights, 5.74 and $0.34 \mathrm{~g}$ compared with other test treatments 30 days after nematode inoculation. Treatment with BABA 3 days before nematode inoculation produced the lowest Rfw and Rdw, 3.96 and 0.29 g respectively 30 days after nematode inoculation. The $40 \mathrm{mM}$ concentration also recorded the lowest root weights, 2.35 and $0.21 \mathrm{~g}$ compared with the highest root weight, 12.98 and $0.80 \mathrm{~g}$ when the treatment was performed 7 days after nematode inoculation.

\subsubsection{Effect of BABA on Fresh and Dry Weight of Shoot Systems}

Spraying of BABA on foliage of tomato plants significantly $(p=0.05)$ increased root fresh and dry weight (Sfw and Sdw) of nematode infected tomato plants 30 days after inoculation (Table 3). The average weights for plants treated with 40 and $20 \mathrm{mM}$ of BABA recorded the highest, 21.40 and $2.10 \mathrm{~g} \mathrm{Sfw}$ and Sdw compared with the lowest average weights of 15.05 and $0.97 \mathrm{~g}$ in nematode infected controls. Treatment with BABA 3 days before nematode inoculation caused significantly the highest weight, 20.99 and 2.24 g compared with 14.24, 0.75, 19.31 and $1.35 \mathrm{~g}$ when nematode was inoculated during and 7 days after BABA treatment respectively. Treatment with 40 and $20 \mathrm{mM}$ of BABA 3 days prior to nematode inoculation caused higher Sfw and Sdw, 25.32, 3.25 and 22.22, $3.90 \mathrm{~g}$ compared with, 12.86 and $0.51 \mathrm{~g}$ for nematode infected control plants respectively.

\subsection{Soil Application}

\subsubsection{Effectof Soil Drenching with BABA on Meloidogyne spp Rate of Gall Index}

Soil drenching with BABA significantly $(p=0.05)$ reduced the root gall index of tomato plants infected with Meloidogyne spp (Table 4). Gall index was decreased as the test BABA concentration was increased. The $5 \mathrm{mM}$ concentration produced significantly the lowest average gall index, 2.33 compared with, 2.77, 3.55 and 5 for 2.5, $1 \mathrm{mM}$ and control 30 days after nematode inoculation respectively. The lowest average gall index, 2.91 was recorded when BABA was applied 3 days before nematode
Table 2. Effect of spraying BABA on tomato, Solanum lycopersicum L. shoot on root weights of Meloidogyne spp infected plants 30 days after nematode inoculation.

\begin{tabular}{|c|c|c|c|c|c|c|c|c|}
\hline \multirow{4}{*}{$\begin{array}{l}\text { BABA } \\
\text { Conc. } \\
\text { (mM) }\end{array}$} & \multicolumn{6}{|c|}{ Root weight of infected plants (g) } & \multirow{4}{*}{$\begin{array}{c}\text { Mean } \\
\text { Dry }\end{array}$} & \multirow{4}{*}{$\begin{array}{l}\text { Mean } \\
\text { Fresh }\end{array}$} \\
\hline & \multicolumn{6}{|c|}{ Nematode inoculation } & & \\
\hline & \multicolumn{2}{|c|}{7 days after } & \multicolumn{2}{|c|}{ During } & \multicolumn{2}{|c|}{3 days before } & & \\
\hline & Dry & Fresh & Dry & Fresh & Dry & Fresh & & \\
\hline 40 & 0.21 & 2.35 & 0.37 & 5.97 & 0.45 & 8.90 & 0.34 & 5.74 \\
\hline 20 & 0.24 & 2.72 & 0.40 & 5.98 & 0.47 & 10.09 & 0.37 & 6.26 \\
\hline 10 & 0.28 & 3.91 & 0.50 & 6.74 & 0.51 & 10.16 & 0.43 & 6.94 \\
\hline 5 & 0.30 & 5.89 & 0.72 & 8.92 & 0.50 & 11.44 & 0.51 & 8.75 \\
\hline Control & 0.40 & 4.94 & 0.52 & 8.79 & 0.80 & 12.98 & 0.58 & 8.90 \\
\hline Mean & 0.29 & 3.96 & 0.50 & 7.28 & 0.54 & 10.71 & & \\
\hline
\end{tabular}

LSD $(P=0.05)$ Dry weight: Conc. $=0.065^{*}$, Treat. $=0.050^{*}$, Inter. $=0.11^{*}$ LSD $(P=0.05)$ Fresh weight: Conc. $=1.78^{*}$, Traet. $=1.37^{*}$, Inter. $=3.08^{*}$. Each number is a mean of three replicates and two plant each. "Indicate significant deferens. Nematode inoculums (nematode infested soil + peat moss, 1:1) were added when plants were $4-5$ true leaves. $\mathrm{BABA}=\beta$, amino butyric acid.

Table 3. Effect of spraying BABA on tomato, Solanum lycopersicum L. shoot on shoot weights of Meloidogyne spp infected plants 30 days after nematode inoculation.

\begin{tabular}{|c|c|c|c|c|c|c|c|c|}
\hline \multirow{4}{*}{$\begin{array}{c}\text { BABA } \\
\text { Conc. } \\
(\mathrm{mM})\end{array}$} & \multicolumn{6}{|c|}{ Shoot weight of infected plants (g) } & \multirow{4}{*}{$\begin{array}{c}\text { Mean } \\
\text { Dry }\end{array}$} & \multirow{4}{*}{$\begin{array}{l}\text { Mean } \\
\text { Fresh }\end{array}$} \\
\hline & \multicolumn{6}{|c|}{ Nematode inoculation } & & \\
\hline & \multicolumn{2}{|c|}{3 days before } & \multicolumn{2}{|c|}{ During } & \multicolumn{2}{|c|}{7 dayd after } & & \\
\hline & Dry & Fresh & Dry & Fresh & Dry & Fresh & & \\
\hline 40 & 3.25 & 25.32 & 1.15 & 13.69 & 1.92 & 25.13 & 2.10 & 21.38 \\
\hline 20 & 2.90 & 22.22 & 1.00 & 17.92 & 1.26 & 24.06 & 1.72 & 21.40 \\
\hline 10 & 1.39 & 21.23 & 0.57 & 12.88 & 1.31 & 14.31 & 1.09 & 16.14 \\
\hline 5 & 2.27 & 18.34 & 0.53 & 13.88 & 1.24 & 18.58 & 1.35 & 16.93 \\
\hline Control & 1.40 & 17.83 & 0.51 & 12.86 & 1.00 & 14.48 & 0.97 & 15.05 \\
\hline Mean & 2.24 & 20.99 & 0.75 & 14.24 & 1.35 & 19.31 & & \\
\hline
\end{tabular}

LSD $(P=0.05)$ Dry weight: Conc. $=0.2669^{*}$, Treat. $=0.2067^{*}$, Inter. $=$ $0.4623^{*}$. LSD $(P=0.05)$ Fresh weight: Conc. $=3.20^{*}$, Treat. $=2.4^{*}$, Inter. $=$ $5.54^{*}$. Each number is a mean of three replicates and two plant each. *Indicate significant deferens. Nematode inoculums (nematode infested soil + peat moss, $1: 1$ ) were added when plants were $4-5$ true leaves $. \mathrm{BABA}=\beta$ amino butyric acid.

inoculation compared to 3.25 and 4.08 when BABA was applied during or 7 days after the nematode respectively. The lowest gall index, 1.66 was caused by application of $5 \mathrm{mM}$ of BABA 3 days before nematode inoculation compared with the highest gall index, 5 in nematode infected control.

\subsubsection{Effect of Soil Drenching with BABA on Weight of Roots}

Results in Table 5 showed that soil drenching with 5 
Table 4. Effect of soil drenching of BABA on rate of root gall index caused by Meloidogyne spp on tomato, Solanum lycopersicum $\mathrm{L}$. 30 days after nematode inoculation.

\begin{tabular}{ccccc}
\hline \multirow{2}{*}{$\begin{array}{c}\text { BABA Conc. } \\
(\mathrm{mM})\end{array}$} & \multicolumn{3}{c}{ Rate of root gall index } & \multirow{2}{*}{ Mean } \\
\cline { 2 - 4 } & 3 days before & During & 7 days after & \\
\hline 5 & 1.66 & 2.33 & 3 & 2.33 \\
2.5 & 2 & 2.66 & 3.66 & 2.77 \\
1 & 3 & 3 & 4.66 & 3.55 \\
Control & 5 & 5 & 5 & 5 \\
Mean & 2.91 & 3.25 & 4.08 & \\
\hline
\end{tabular}

LSD $(P=0.05)$ Conc. $=0.36^{*}$, Treat. $=0.31^{*}$, Inter. $=0.62^{*}$ Each number is a mean of three replicates and two plant each. ${ }^{*}$ indicate significant deferens. Nematode inoculums (nematode infested soil + peat moss, 1:1) were added when plants were 4 - 5 true leaves. Gall index was according to 1 - 5 level scale: $1=$ no galls on the roots, 2 = galls on $1 \%-25 \%$ of the root , $3=$ galls on $26 \%-50 \%$ of the root, $4=$ galls on $51 \%-75 \%$ of the root, and $5=$ galls on $76 \%-100 \%$ of roots. BABA $=\beta$, amino butyric acid.

Table 5. Effect of soil drenching of BABA on root weights of tomato, Solanum lycopersicum L. infected with Meloidogyne spp 30 days after nematode inoculation.

\begin{tabular}{|c|c|c|c|c|c|c|c|c|}
\hline \multirow{4}{*}{$\begin{array}{l}\text { BABA } \\
\text { Conc. } \\
\text { (mM) }\end{array}$} & \multicolumn{6}{|c|}{ Root weight (g) } & \multirow{4}{*}{$\begin{array}{c}\text { Mean } \\
\text { Dry }\end{array}$} & \multirow{4}{*}{$\begin{array}{l}\text { Mean } \\
\text { Fresh }\end{array}$} \\
\hline & \multicolumn{6}{|c|}{ Nematode inoculation } & & \\
\hline & \multicolumn{2}{|c|}{3 days before } & \multicolumn{2}{|c|}{ During } & \multicolumn{2}{|c|}{7 days after } & & \\
\hline & Dry & Fresh & Dry & Fresh & Dry & Fresh & & \\
\hline 5 & 0.27 & 3.25 & 0.34 & 3.72 & 0.39 & 9.86 & 0.35 & 5.61 \\
\hline 2.5 & 0.16 & 2.50 & 0.39 & 8.98 & 0.51 & 9.44 & 0.35 & 6.97 \\
\hline 1 & 0.32 & 3.37 & 0.49 & 11.39 & 0.52 & 9.43 & 0.43 & 8.06 \\
\hline Control & 0.35 & 3.75 & 0.36 & 10.23 & 0.61 & 9.77 & 0.44 & 7.91 \\
\hline Mean & 0.28 & 3.21 & 0.39 & 8.58 & 0.51 & 9.62 & & \\
\hline
\end{tabular}

LSD $(P=0.05)$ Fresh weight: Conc. $=1.41^{*}$, Traet. $=1.22^{*}$, Inter. $=2.44^{*}$. LSD $(P=0.05)$ Dry weight: Conc. $=0.0724^{*}$, Inter. $=0.1447^{*}$. Each number is a mean of three replicates and two plant each. Indicate significant deferens. Nematode inoculums (nematode infested soil + peat moss, 1:1) were added when plants were $4-5$ true leaves. $\mathrm{BABA}=\beta$, amino butyric acid.

mM BABA significantly $(p=0.05)$ affected Rfw and Rdw of Meloidogyne spp infected tomato plants. At this concentration average Rfw and Rdw were 5.61 and 0.35 g compared with 7.91 and $0.44 \mathrm{~g}$ in control plants respectively. However, 2.5 and $1 \mathrm{mM}$ did not significantly affect root weights. The $40 \mathrm{mM}$ recorded the lowest average root weights, 5.74 and $0.34 \mathrm{~g}$ compared with other test treatments 30 days after nematode inoculation. Treatment with BABA 3 days before nematode inoculation produced the lowest average Rfw and Rdw, 3.21 and $0.28 \mathrm{~g}$ compared with $8.58,0.39,9.62$ and $0.51 \mathrm{~g}$ at the time and 7 days after nematode inoculation respectively.
While the lowest root weights were recorded for the 5 and $2.5 \mathrm{mM}, 3$ days before nematode inoculation, 3.25, $0.27,2.50,0.16$, the $1 \mathrm{mM}$ concentration and control recorded the highest root weights, 11.39, 0.49, 10.23, $0.36 \mathrm{~g}$ respectively when the treatment was performed at the timeof nematode inoculation.

\subsubsection{Effect of Soil Drenching with BABA on Weight of Shoots}

Soil drenching with the test concentrations of BABA significantly $(p=0.05)$ affected shoot weights of Meloidogyne infected tomato plants (Table 6). The average Sfw and Sdw was grater, 20.43 and $2.34 \mathrm{~g}$ in $5 \mathrm{mM}$ treatment compared with 15.11 and $1.19 \mathrm{~g}$ in control. Grater shoot weights were observed when BABA treatments exceeded nematode inoculation by 3 days , 20.91, 2.65 compared with 13.11, 0.70 and 18.61, $1.52 \mathrm{~g}$ when BABA treatment was at or 7 days after nematode inoculation respectively. The greatest average Sfw and Sdw, 24.32 and $4.22 \mathrm{~g}$ were recorded for $5 \mathrm{mM}$ application 3 days before nematode inoculation while the lowest Sdw, $0.43 \mathrm{~g}$ and $\mathrm{Sfw}, 11.75 \mathrm{~g}$ for the $1 \mathrm{mM}$ at the time of nematode inoculation and the untreated control plants respectively.

\section{DISCUSSION}

Results of this work indicated that foliage as well as soil drench application of BABA induced systemic resistance against Meloigogyne spp in susceptible tomato plants. This was manifested by the reduction of galls on roots and numbers of $\mathrm{J} 2$ in roots of BABA treated plants compared with those in BABA untreated but nematode

Table 6. Effect of soil drenching of BABA on shoot weights of tomato, Solanum lycopersicum L. infected with Meloidogyne spp 30 days after nematode inoculation.

\begin{tabular}{|c|c|c|c|c|c|c|c|c|}
\hline \multirow{4}{*}{$\begin{array}{l}\text { BABA } \\
\text { Conc. } \\
\text { (mM) }\end{array}$} & \multicolumn{6}{|c|}{ Shoot weight (g) } & \multirow{4}{*}{$\begin{array}{l}\text { Mean } \\
\text { Dry }\end{array}$} & \multirow{4}{*}{$\begin{array}{l}\text { Mean } \\
\text { Fresh }\end{array}$} \\
\hline & \multicolumn{6}{|c|}{ Nematode inoculation } & & \\
\hline & \multicolumn{2}{|c|}{3 days before } & \multicolumn{2}{|c|}{ During } & \multicolumn{2}{|c|}{7 days after } & & \\
\hline & Dry & Fresh & Dry & Fresh & Dry & Fresh & & \\
\hline 5 & 4.22 & 24.32 & 1.09 & 16.47 & 1.71 & 20.50 & 2.34 & 20.43 \\
\hline 2.5 & 2.76 & 22.92 & 0.75 & 11.96 & 1.64 & 20.90 & 1.71 & 18.59 \\
\hline 1 & 1.90 & 20.51 & 0.43 & 12.25 & 1.45 & 15.39 & 1.26 & 16.05 \\
\hline Control & 1.73 & 15.89 & 0.53 & 11.75 & 1.30 & 17.67 & 1.19 & 15.11 \\
\hline Mean & 2.65 & 20.91 & 0.70 & 13.11 & 1.52 & 18.61 & & \\
\hline
\end{tabular}

LSD $(P=0.05)$ Fresh weight: Conc. $=2.50^{*}$, Traet. $=2.16^{*}$, Inter. $=4.33^{*}$ LSD $(P=0.05)$ Dry weight: Conc. $=0.319^{*}$,Treat. $=0.2763^{*}$, Inter. $=$ $0.5252^{*}$. Each number is a mean of three replicates and two plant each. * Indicate significant deferens. Nematode inoculums (nematode infested soil + peat moss, 1:1) were added when plants were 4 - 5 true leaves. . BABA = $\beta$,amino butyric acid. 
infected plants. The growth of the nematode infected plants by decreasing root weight and increasing shoot weight of BABA treated tomato plants. These findings also support previous reports indicating that treatments with $\beta$,amino butyric acid reduced root knot disease through decreased penetration of J2, gall number on roots and nematode development $[4,11,12]$. Root weight increase in heavy Meloidogyne spp infection was previously reported and thought to be caused due to biomass accumulations in infected roots [16]. Meloigogyne spp infection is known to have negative effects on water and nutrient elements as well as photosynthesis [17]. It was reported that $M$. incognita infection caused biomass accumulation in roots and this is controlled by the efficiency of the pathogen in capturing the light energy and directing it in favor of the pathogen or the infected host [18]. Because of the relative large size of females of Meloigogyne spp and its ability to produce large number of eggs, it requires large amount of energy. Beside this energy requirement, these pathogens caused obvious distortion in xylem vessels, swellings of root cells and formation of giant feeding cells which alter root normal functions. Treatments of nematode infected plants with the high concentration of BABA produced more shoots compared with untreated nematode infected plant. This is mainly due to the fact that Meloidogyne infections embed photosynthesis and chlorophyll synthesis which negatively influences plant growth [17]. It was clear from the results of this study that treatments with BABA was more effective when applied before nematode inoculation, which is probably due to the mechanism of induce resistance of this chemical inducer. The mechanism of induce resistance to Meloidogyne in tomato by BABA is not fully understood. It was believed that treatments with this inducer render roots less attractive to J2 through altered plant nutrient assimilation or render plant cell walls harder to penetrate by $\mathrm{J} 2$ or that giant cells were smaller or not able to provide enough nutrients for the developing nematodes [11]. Treatments with BABA were reported to increase levels of salicylic acid (SA) and pathogenesis related proteins (PRP) [19], and enzymes like catalase (CAT), polyphenoloxidase (PPO) and guaiacol peroxidase (GPOX) [4,7] and phenol compounds [20]. BABA was also reported to induce the accumulations of PPO, GPOX, $\mathrm{H}_{2} \mathrm{O}_{2}$, CAT and phenols in M.javanica infected cucumber roots [21].

Results of this research work clearly indicate and indorse previous reports on the effectiveness of $\beta$,aminobutyric acid to the induced systemic resistance as environmentally sound alternative for the control of Meloidogyne spp on tomato.

\section{ACKNOWLEDGEMENTS}

The authors would like to thank Mr. Dhulfiqar Layth (Graduate stu- dent, Dept., of Plant Protection, College of Agriculture,Univ. of Baghdad, Baghdad, Iraq) for his valuable assistance.

\section{REFERENCES}

[1] Anonymos (2009) www.Frehplaza.com/news.

[2] FAOSTAT (2008) List of countries by tomato production. https://www.google.com/search

[3] Kumagai, T. (1988) Photocontrol of fungal development. Photochemistry and Photobiology, 47, 889-896. http://dx.doi.org/10.1111/j.1751-1097.1988.tb01672.x

[4] Sahebani, N. and Hadavi, N.S. (2011) The effects of $\beta$-amino-butyric acid on resistance of cucumber against root-knot nematode, Meloidogyne javanica. Journal of Plant Physiology, 33, 443-450.

[5] Gorlach, J., Volrath, S., Knauf-Beiter, G., Hengy, G., Beckhove, U., Kogel, Oostendorp, M., Staub, T., Ward, E., Kessmann, H. and Ryals, J. (1996) Benzothiadiazole, a novel class of inducers of systemic acquired resistance, activates gene expression and disease resistance in wheat. Plant Cell, 8, 629-643.

[6] He, C.Y. and Wolyn, D.J. (2005) Potential role for salicylic acid in inducedresistance of asparagus roots to Fusariumoxysporumf. sp. asparagi. Plant Pathol. 54, 227232. http://dx.doi.org/10.1111/j.1365-3059.2005.01163.x

[7] Sahebani, N. and Hadavi, N.S. (2009) Induction of $\mathrm{H}_{2} \mathrm{O}_{2}$ and related enzymes in tomato roots infected with root knot nematode (M. javanica) by several chemical and microbial elicitors. Biocontrol Science and Technology, 19, 301-313.

[8] Kessmann, H., Staub, T., Hofmann, C., Maetzke, T., Herzog, J., Ward, E., Uknes, S. and Ryals, J. (1994) Induction of systemic acquired resistancein plants by chemicals. Annual Review of Phytopathology, 32, 439-459.

[9] Cohen, Y. (2002) $\beta$-aminobutyric acid-induced resistance against plant pathogens. Plant Disease, 86, 448-457. http://dx.doi.org/10.1094/PDIS.2002.86.5.448

[10] Jacab, G., Cottrier, V., Toquin, V., Rigoli, G., Zimmerli, L., Metraux, J.P. and Mauch-Mani, B. (2001) $\beta$-aminobutyric acid-induced resistance in plants. European Journal of Plant Pathology, 107, 29-37. http://dx.doi.org/10.1023/A:1008730721037

[11] Oka, Y, Cohen, Y. and Speigel, Y. (1999) Local and systemic inducec resistance to the root-knot nematode in tomato by DL-b-aminon-butyric acid. Phytopathology, 89, $1138-1143$.

http://dx.doi.org/10.1094/PHYTO.1999.89.12.1138

[12] Chinnasri, B., Sipes, B.S. and Schmitt, D. P. (2006) Effect of inducer of systemic acquired resistance on reproduction of Meloidogyne javanica. Journal of Nematology, 38, 319-325.

[13] Dube, B. and Smart, G.C.J. (1987) Biological control of Meloidogyne incognita by paecilomyceslilacinuc and pasturiapenetrans. Journal of Nematology, 9, 222-227.

[14] Byrd, D.W., Kirkpatrick, T., Barker, K.R. (1983) An improved technique for learing and staining plant tissue for detection of nematodes. Journal of Nematology, 15, 142- 
143.

[15] SAS (2004) SAS user's guide for personal, computers. SAS Institute Inc., Cary.

[16] Fortnum, B.A., Decoteau, D.R., Kasperbauer, M.J. and Bridges, W. (1995) Effect of colored mulch on rootknot of tomato. Phytopathology, 85, 312-318. http://dx.doi.org/10.1094/Phyto-85-312

[17] Melakeberhan, H. (2004) Physiological interactions between Nematodes and Their Host Plants. In: Chen, Z.X., Chen, S.Y. and Dickson, D.W., Eds., Nematode Management and Utilization II, CABI Publishing, p. 786.

[18] Melakebrhan, H. and Ferris, H. (1988) Growth and energy demand of Meloidogyne incognita on susceptible and resistance Vitis vinifera cultivars. Journal of Nematology, 20, 545-554.

[19] Hwang, B.K., Sunwoo, J.Y., Kim, Y.J. and Kim, B.S.
(1997) Accumulation of beta-1,3-glucanase and chitinase isoforms, and salicylic acid in the DL-beta-amino-n-butyric acid-induced resistance response of pepper stems to Phytophthoracapsici. Physiological and Molecular Plant Pathology, 51, 305-322. http://dx.doi.org/10.1006/pmpp.1997.0119

[20] M’Piga, P., Belanger, R.R., Paulitz, T. and Benhamou, N. (1997) Increasedresistance to Fusariumoxysporum f. sp. radicis-lycopersici in tomato plants treated with the endophytic bacterium Pseudomonas fluorescens strain 6328. Physiological and Molecular Plant Pathology, 50 301-320. http://dx.doi.org/10.1006/pmpp.1997.0088

[21] Siegrist, J., Orober M. and Buchenauer, H. (2000) $\beta$ amino butyric acid mediated enhancement of resistance in tobacco to tobaccomosaic virus depends on the accumulation of salicylic acid. Physiological and Molecular Plant Pathology, 56, 95-106. 